\title{
La incidencia de la dotación de infraestructuras para los servicios públicos en red en el precio del suelo: evidencia del Gran Buenos Aires
}

Lucas Ronconi. Centro de Investigación y Acción Social (CIAS) y Consejo Nacional de Investigaciones Científicas y Técnicas (Conicet), Buenos Aires, Argentina.

Juan Casazza. Subsecretaría Social de Tierras, Urbanismo y Vivienda, Buenos Aires, Argentina.

Eduardo Reese. Universidad Nacional de General Sarmiento, Buenos Aires, Argentina.

RESUMEN | Utilizando una muestra de cerca de 600 lotes localizados en municipios del Gran Buenos Aires (GBA), se estima la incidencia que tiene la dotación de infraestructuras para los servicios públicos en red, como cloacas, gas en red, pavimento y electricidad, sobre el precio de los lotes. Los estimadores sugieren que la provisión de infraestructura tiene un efecto positivo sobre el valor de la propiedad que supera el costo de construcción, particularmente entre los lotes geográficamente mejor ubicados. Se analiza, asimismo, la sensibilidad de los estimadores a problemas de variable omitida. Estos resultados sugieren que la contribución por mejora basada en la valorización del inmueble, una herramienta que no se utiliza en el GBA, puede constituirse en un instrumento eficaz de financiamiento.

PALABRAs ClAVE | mercado de suelo, redes, economía urbana.

ABSTRACT | In this article, the authors estimate the effect of investment on infrastructure (i.e., sewerage, gas provision, paved streets and electricity) on the price of land using a sample of almost 600 lots located in Greater Buenos Aires (GBA). The estimates suggest that effects are positive and larger than the cost of construction, particularly among the lots with the best locations. We also explore the robustness of the results to omitted variable bias. These results suggest that betterment levies, which are seldom used in GBA, could become an effective financial tool in some cases.

KEYWORDs | land market, networks, urban economy. 


\section{Introducción}

Los procesos de desarrollo urbano de las ciudades latinoamericanas en general, y de las argentinas en particular, se han distinguido por la incapacidad estructural que presentaron históricamente en materia de producción universal de infraestructuras, de equipamientos y de viviendas asequibles a todos los sectores sociales. Esta característica ha sido particularmente notable en los momentos de rápido crecimiento físico y demográfico, que ensancharon las brechas entre oferta y demanda de servicios básicos e incrementaron las carencias, especialmente de la población de menores recursos.

Lo anterior tiene una fuerte interrelación con tres cuestiones reiteradamente señaladas en la bibliografía: primero, los altos precios del suelo urbanizado y equipado, que se verifican en relación con los ingresos medios de la población; segundo, las amplias disparidades que muestran los precios del suelo entre distintos sectores urbanos que cuentan con diferentes niveles de cobertura de redes de servicios; tercero, las fuertes desigualdades que caracterizan la configuración socioterritorial de los centros urbanos, explicables, en parte, por los dos factores anteriores.

Al mismo tiempo, existe relativo consenso en la literatura respecto a la conveniencia de financiar los procesos de desarrollo urbano a través de instrumentos que capturen, por lo menos en parte, los incrementos en el precio de las propiedades que generan las redes de servicios públicos. La provisión de servicios en red de agua, gas, cloacas, desagües pluviales, alumbrado y pavimentación, por citar algunos ejemplos, beneficia indirectamente a la población en su conjunto, producto de sus externalidades positivas; $y$, al mismo tiempo, produce beneficios directos que son apropiados por los dueños de los terrenos que reciben el servicio. Estos beneficios se traducen en incrementos en el valor de la propiedad.

En el marco general descripto, el objetivo del presente estudio consiste en cuantificar el impacto que tiene la provisión de diferentes redes de servicios públicos sobre el precio de los terrenos en áreas de expansión urbana. Para ello, los análisis se focalizaron en dos municipios del segundo cordón de expansión del Gran Buenos Aires: Berazategui y Florencio Varela. Adicionalmente, este estudio tiene como finalidades complementarias analizar la heterogeneidad de las valorizaciones producidas por la provisión de infraestructuras en función de la localización de los predios; estimar la relación existente entre las valorizaciones producidas y los costos de construcción de las distintas redes; y servir de insumo para los encargados de política pública interesados en implementar instrumentos de captura de las valorizaciones destinadas al financiamiento equitativo de la gestión urbana.

El uso de instrumentos de captura de valorización inmobiliaria en Argentina, si bien presenta diferencias según jurisdicción, es en general de alcance muy limitado, especialmente desde los años ochenta del siglo pasado. En particular, en los municipios del Gran Buenos Aires se cobra al propietario del terreno solo un porcentaje del costo de la obra o no se cobra nada, mientras que la evidencia que se presenta en este estudio indica que los terrenos se valorizan por un monto sustancialmente superior al costo de la obra. Es decir, hay un amplio margen para mejorar la política pública 
a través de la implementación de instrumentos que recuperen la valorización inmobiliaria generada por la inversión en obra pública.

\section{Contribución de mejoras como instrumento de financiación de la obra pública}

La contribución de mejoras (en adelante CM), también conocida como contribución por valorización, constituyó históricamente un instrumento relevante para la financiación de la infraestructura urbana en una parte apreciable de las ciudades latinoamericanas, aun cuando su aplicación fuera parcial y discontinua debido a los frecuentes cambios de políticas ocurridos. Según Smolka y Amborski (2003), "las contribuciones impuestas a los propietarios de la tierra que se benefician de alguna forma de inversión pública son la forma más reconocida de recuperación de plusvalías. En América Latina, la aplicación de este tipo de instrumento puede rastrearse hasta tiempos coloniales..." (pp. 58-59).

En el texto clásico de Jorge Macón (1972) se define la contribución de mejoras como aquella que "grava el aumento de valor que se opera en la propiedad inmueble como consecuencia de las obras que construye el sector público" (p. 3). En igual sentido, para Marienhoff (1975), la contribución por mejoras es "el tributo que se le paga al Estado en retribución de la plusvalía o aumento de valor que, a raíz de la construcción de una obra pública, experimenten las propiedades privadas aledañas, fronteras o inmediatas a dicha obra" (Tomo II, pp. 53-54).

Así, y basado en el principio general de que los beneficios deben ser distribuidos en forma proporcional al esfuerzo de cada propietario, la CM tiene la función de recuperar para el sector público por lo menos una parte del incremento del precio del inmueble que se deriva de la construcción de una obra pública y que se destina a financiar la propia obra que le da origen. Por otro lado, la justificación de la CM puede asimismo encontrarse en la teoría del enriquecimiento sin causa.

\section{Caracterización del Área Metropolitana de Buenos Aires}

El Área Metropolitana de Buenos Aires (АмВА) es el aglomerado más importante del sistema urbano argentino y, con más de 13 millones de habitantes (según el censo del año 2010), concentra alrededor del 35\% de la población total del país (lo que corresponde al 38\% de la población urbana). La conurbación está conformada por la Ciudad Autónoma de Buenos Aires (CABA) y 24 municipios de la Provincia de Buenos Aires que constituyen el GBA y ocupan una superficie aproximada de $2.700 \mathrm{~km}^{2}$, de los cuales cerca de $2.100 \mathrm{~km}^{2}$ se encuentran urbanizados.

Algunos de los elementos estructurales que caracterizan el Área Metropolitana son:

- Primero, la conformación de un área central a partir de la cual se expandió y que históricamente ha sido sede de las más importantes actividades. La CABA cuenta con una cobertura completa de los servicios urbanos, y a su vez articula un amplio espectro de actividades terciarias que determina intensos flujos diarios pendulares entre los lugares de residencia y empleo. 
- Segundo, el carácter radial del sistema de circulación y transporte, hacia y desde el área central, que orientó tradicionalmente el proceso de urbanización metropolitano y promovió la concentración de importantes alineamientos comerciales y de servicios en sus principales corredores.

- Tercero, la matriz de urbanización, un damero expandido que sirve de soporte al uso residencial y que contiene, a partir de la articulación con el sistema de transporte público, diferentes subcentros. Las condiciones de centralidad de estos son de fuerte relevancia en términos de la organización general metropolitana y cumplen importantes funciones como áreas de servicio del tejido residencial circundante. En ese marco, cada subcentralidad es la cabecera de un municipio metropolitano, como en los casos de Berazategui y Florencio Varela.

- Cuarto, la trama urbanizada, que presenta una gran variabilidad interna de densidades, coexistiendo espacios de elevada concentración de actividades urbanas con otros de carácter semirrural. Asimismo la urbanización metropolitana condensa muy altos niveles de contrastes sociales, coexistiendo numerosos y sobrepoblados "bolsones" de pobreza con áreas residenciales y de consumo de los sectores con mayor nivel de ingreso del país. A su vez, la cobertura de redes de servicios urbanos en general sigue un gradiente decreciente (también tradicional de nuestras ciudades) del centro hacia la periferia, donde se ubican Berazategui y Florencio Varela.

El crecimiento amanzanado expansivo respondió casi exclusivamente a los mecanismos del mercado y al predominio de intereses en gran medida especulativos. El modelo de crecimiento histórico estuvo basado en el loteo popular a bajo precio con escasos niveles de cobertura de infraestructura y, en determinados períodos históricos, en bajas tarifas de transporte para los usuarios (basadas en políticas de subsidios a empresas públicas de servicios). ${ }^{1}$ El loteo popular se constituyó así en el mecanismo principal con el cual se expandieron en forma extensiva las tramas urbanas.

\section{El mercado del suelo en el AMBA en los últimos años}

El crecimiento continuo de la ciudad, con la consecuente conversión de tierra rural en tierra urbana, se llevó a cabo en el marco de escasas y dispersas reglamentaciones de orden provincial y municipal. A partir de finales de los ańos setenta del siglo pasado, el modelo tradicional de crecimiento urbano metropolitano a través del loteo popular comenzó a experimentar cambios significativos, fundamentalmente por dos causas: primero, la aprobación durante el gobierno militar en 1977 del Decreto Ley 8912, el cual determinó el cumplimiento de estándares de urbanización más rigurosos que restringieron la subdivisión de la tierra sin redes de infraestructura, con la consecuente elevación de los precios; segundo, el aumento en la pobreza y la precariedad laboral debido a las malas políticas sociales y económicas

1 Se entiende por "loteo popular" al fraccionamiento, urbanización mínima y venta en mensualidades, promovido por agentes privados, de parcelas de tierra destinadas a la vivienda de los sectores de bajos ingresos. 
que impactaron sobre el mercado laboral y sobre las condiciones de vida de los sectores medios y populares.

A partir de los años noventa, durante un gobierno democrático caracterizado por desregular diversas áreas de la economía, la mejora de la infraestructura vial por el régimen de concesiones de autovías y autopistas permitió la incorporación de nuevos territorios de borde, absorbiendo las áreas rurales que no pudieron competir con la proliferación de nuevos emprendimientos dirigidos al consumo de los sectores de altos ingresos, y que dieron lugar a la aparición de diferentes enclaves en intersticios vacantes o en los bordes de expansión del tejido metropolitano. Las nuevas y/o ampliadas vías rápidas resultaron ser el elemento clave de la expansión periférica. Estas transformaciones, tal como plantea Torres (1993, 2001), marcaron la difusión de nuevas pautas de organización territorial que produjeron, por una parte, una fuerte concentración de inversiones en ámbitos precisos, considerados como "espacios estratégicos" a nivel urbano; y, por otra, significaron un relativo abandono de amplias zonas que fueron consideradas como residuales y que no resultaban de interés para los inversores.

Fue así que en el AMBA se produjeron nuevos patrones de urbanización residencial (a través de distintas formas de enclaves suburbanos de alto estándar, denominados genéricamente "barrios cerrados"), acompañados por la expansión, también periférica, del sector terciario de consumo y esparcimiento (shoppings centers, hipermercados, parques recreativos, etcétera) y del sector productivo (parques industriales, parques empresariales, etcétera).

Estos procesos han promovido una fuerte valorización del suelo urbano y periurbano y la generación de nuevas formas de fragmentación del territorio. En los últimos veinte ańos el mercado de tierras se amplió a una escala desconocida, incorporando nuevas superficies aptas para estos emprendimientos y afectando diferencialmente el territorio del aglomerado. En todos los casos, los emprendimientos se ubican en tierras intersticiales de las periferias sobre las que en general se asentaba tradicionalmente la población de menores recursos. Esto hizo imposible para los sectores populares el acceso a esas tierras revalorizadas y generó un nuevo tipo de segregación. De esta forma, los conflictos sociales, urbanos y ambientales, consecuencia de los nuevos procesos, se superponen con aquellos heredados y no resueltos del anterior modelo de crecimiento.

Luego de la severa crisis que sufrió el país en el período 2001-2002, y a partir del crecimiento económico, el mercado de inmuebles en la Argentina en general, y en el AмBa en particular, mostró mayor dinamismo. Asimismo, hubo cambios importantes en el papel del Estado, que reasumió un rol activo en diversas políticas, fundamentalmente de transferencias monetarias a los sectores más pobres. Sin embargo, como señalan Baer y Kauw (2016), el problema habitacional y de acceso al suelo formal con buenos servicios se ha agravado.

Si bien la propiedad inmueble siempre tuvo en la Argentina un rol muy importante como reserva de valor tanto para las familias como para los inversores, frente a las incertidumbres que presentaban los cambios económicos, con posterioridad a la crisis de los años 2001 y 2002 esta tendencia se generalizó, con una escala que los especialistas destacan de manera particular. Esto, a su vez, se robusteció a partir 
de la implementación de una política de tasa de interés real negativa impulsada por el gobierno. En este marco de renovada capacidad adquisitiva de los sectores de ingresos medios altos y altos en Argentina, la inversión en propiedad raíz se constituyó en el mecanismo privilegiado de ahorro y preservación de valor. Esto explica la profundización de un proceso que se había iniciado en los años noventa del siglo pasado: la fuerte concentración en dichos sectores de la oferta de productos de alto estándar del mercado inmobiliario.

Por último, la concentración inmobiliaria en los sectores de mayores ingresos encuentra también parte de su explicación en la muy reducida oferta de financiamiento hipotecario que afectó en los últimos diez años especialmente a los sectores medios y medios bajos con alguna capacidad de ahorro. La evolución del crédito hipotecario con destino a la vivienda en la Argentina registró un quiebre en el año 2002, a partir de la pesificación de los créditos originalmente pactados en dólares, cayendo de 10 mil millones de dólares a 2 mil millones. En relación con la proporción de escrituras financiadas con créditos hipotecarios, luego de haberse mantenido durante el período $1994-2001$ en un rango de entre el $25 \%$ y el $35 \%$, y de haber caído por debajo del 4\% en los años 2002 y 2003, comenzó una recuperación que la mantuvo cerca del $8 \%$ los últimos años. ${ }^{2}$

\section{Construcción y gestión de servicios públicos y contribución de mejoras en el AMBA}

En el caso de Buenos Aires, la historia de la gestión de los servicios urbanos presenta diferentes momentos y cambios de política: originalmente, entre finales del siglo xIx y principios del xx, dichos servicios fueron actividades a cargo de empresas privadas de capitales y financiamiento extranjero bajo la regulación (como servicios públicos) de los gobiernos locales. A mediados del siglo pasado fueron estatizados por el primer peronismo, en un marco previo de falta de inversión, mala calidad e ineficacia en las prestaciones. Algo más de cuarenta ańos después fueron privatizados en el contexto de una profunda crítica general a la gestión estatal. Así, del pobre desempeño de las empresas públicas, se pasó, durante la década de los noventa, a una gestión de los servicios predominantemente privada, con su potencial diferenciador sobre la estructuración del territorio metropolitano. Este proceso de privatización no fue un simple cambio en el régimen de propiedad, sino una transferencia de funciones de coordinación y de gobierno al sector privado o a concesionarios, sin un sistema articulado de planificación y de control. A partir del año 2003, y como consecuencia de la crisis de los años 2001 y 2002, el modelo privatizador de la década pasada fue puesto en cuestión y se modificó estructuralmente el marco regulatorio y

2 Según datos del Banco Central de la República Argentina y del Instituto Nacional de Estadística y Censos de la República Argentina (INDEC). Los créditos hipotecarios en 2015 representaban menos del 2\% del PBI. 
de control, ${ }^{3}$ reestatizándose, en algunos casos, distintos servicios (como los de agua y saneamiento desde 2006). ${ }^{4}$

TABLA I | Configuración de prestación de servicios en el амва

\begin{tabular}{|c|c|c|}
\hline \multirow{2}{*}{ SERVICIO } & \multicolumn{2}{|c|}{ EMPRESA U ORGANISMO PRESTADOR DEL SERVICIO } \\
\hline & PÚBLICO & PRIVADO \\
\hline $\begin{array}{l}\text { Agua y } \\
\text { saneamiento } \\
\text { cloacal }\end{array}$ & $\begin{array}{l}\text { - Agua y Saneamientos Argentinos S.A. } \\
\text { (AySA) a cargo de CABA y diecisiete } \\
\text { municipios del AMBA. } \\
\text { - Aguas Bonaerenses S.A. (ABSA) a cargo } \\
\text { de diez municipios del AMBA. }\end{array}$ & \\
\hline $\begin{array}{l}\text { Gas natural } \\
\text { por red }\end{array}$ & & $\begin{array}{l}\text { - Gas Natural BAN S.A. a cargo de treinta } \\
\text { municipios de las zonas norte y oeste del } \\
\text { AMBA. } \\
\text { - Metrogas S.A. a cargo de CABA y once } \\
\text { municipios del sur del AMBA. }\end{array}$ \\
\hline Electricidad & & $\begin{array}{l}\text { - Empresa Distribuidora de Energía Sur } \\
\text { S.A. (Edesur S.A): zona sur de CABA y doce } \\
\text { municipios del sur del GBA. } \\
\text { - Empresa Distribuidora y Comercializa- } \\
\text { dora Norte s.A. (Edenor S.A.): zona norte } \\
\text { de CABA y veinte municipios del norte y } \\
\text { oeste del GBA. }\end{array}$ \\
\hline $\begin{array}{l}\text { Pavimento, } \\
\text { alumbrado y } \\
\text { desagües } \\
\text { pluviales }\end{array}$ & Municipios & \\
\hline
\end{tabular}

FUENTE ELABORACIÓN PROPIA

Más allá de los cambios en la gestión de los servicios, el reparto tradicional de responsabilidades en la ejecución de las obras necesarias para la cobertura de la demanda en los municipios del Aмва implicó que el Estado Nacional, el Estado Provincial o las empresas privadas prestatarias (según cada situación) financiaran y llevaran a cabo las obras básicas y estructurales, y los municipios tuvieran el compromiso de desarrollar las obras de extensión domiciliaria a través de distintas modalidades que se explican más abajo. En el lenguaje técnico, esta forma de ejecución de las obras domiciliarias se denominó "obras por cuenta de terceros" u ортC.

3 Especialmente importantes fueron los cuestionamientos a los incumplimientos de los contratos y a los organismos de regulación y control de las empresas privatizadas durante los ańos noventa, en la medida en que fueron incapaces de preservar y fortalecer el carácter público de los servicios esenciales.

4 En el caso del servicio de agua y saneamiento, el proceso histórico resumido es el siguiente: (i) la empresa Obras Sanitarias de la Nación (OSN) fue el prestador estatal a nivel nacional entre 1912 y 1980; (ii) en 1980 se traspasaron a manos de las provincias los servicios, mientras que la empresa quedó como responsable de los mismos en gran parte de los municipios del AMBA; (iii) entre 1993 y 2006 la empresa fue privatizada; (iv) en 2006 se rescindió el contrato al concesionario privado y desde entonces la prestación de los servicios se efectúa a través de la empresa estatal Agua y Saneamientos Argentinos S.A. (Aysa). 
La excepción a esta regla la constituyó la red viaria, en la medida en que dicho servicio fue invariablemente prestado por el sector público, según la jerarquía y "propiedad" de las vías. Así, la pavimentación y mantenimiento de la capa de rodamiento de las rutas nacionales que atraviesan los municipios es responsabilidad del Estado nacional; las provinciales, del gobierno provincial; y las calles y avenidas de cualquier jerarquía de la trama amanzanada, de los gobiernos locales.

Como se puede observar, históricamente los municipios metropolitanos cumplieron una función relevante en la planificación y en la gestión territorial, en la medida en que sobre ellos recayeron siempre las competencias y obligaciones de la extensión de las redes de servicios; y en el caso de la vialidad local, su incumbencia incluyó la provisión del alumbrado público y la construcción de los sistemas de drenaje pluvial (y sus respectivos mantenimientos). ${ }^{5}$

Desde el punto de vista de las modalidades de ejecución de las ортC, el АмBa (al igual que el resto de las ciudades del país) muestra una amplia heterogeneidad. En forma resumida, ellas pueden clasificarse en cuatro modos: (i) por ejecución directa de la Municipalidad, también denominada "por administración"; (ii) por contrato directo entre vecinos y empresas constructoras; (iii) por licitación pública; (iv) por consorcios y/o cooperativas; (v) por combinatoria entre los modos primero, tercero y cuarto.

Adicionalmente, las modalidades señaladas han tenido, a lo largo del tiempo, una muy amplia variedad de formas particulares de implementación, que incluyeron también diversos mecanismos de financiamiento:

a. En cuanto a la modalidad i) (obras por administración), los casos más usuales de ejecución han sido:

- Construcción y financiamiento directo de los municipios con o sin ayuda de financiamiento externo y con o sin recuperación posterior de los costos.

- Construcción con aporte de mano de obra vecinal y provisión de materiales y equipos a cargo del municipio.

- Construcción con aporte de los materiales a cargo de los beneficiarios, quedando la mano de obra y los equipos a cargo del gobierno local.

b. En el caso de las modalidades ii) y iii), en una apreciable cantidad de experiencias los municipios impusieron directamente a la empresa contratista de las obras la percepción de los beneficiarios respecto del costo de la obra. ${ }^{6}$

c. La modalidad iv) ha sido ampliamente utilizada en los últimos diez ańos, como consecuencia de las políticas de fomento del empleo instrumentadas especialmente por el gobierno nacional a través de programas de creación de cooperativas, capacitación laboral y provisión de herramientas. ${ }^{7}$

5 La construcción y mantenimiento de los sistemas de control de inundaciones de las cuencas grandes y medianas que surcan los municipios metropolitanos es responsabilidad de la Dirección de Hidráulica del gobierno provincial.

6 En estos casos, el municipio cumplía la función de control de las obras y los pagos.

7 En particular los dos planes, "Agua + Trabajo" y "Cloacas + Trabajo", llevados a cabo por la empresa Aysa. 
d. En la aplicación de las modalidades anteriores se ensayó también, en algunos municipios, el financiamiento parcial vecinal a través de mecanismos de ahorro previo, a fin de reducir los impactos de los costos financieros de las obras.

e. Asimismo, algunos municipios constituyeron fideicomisos de administración específicos con el fin de garantizar la intangibilidad de los fondos de recupero para el financiamiento de las obras.

En la Argentina, la contribución por mejoras (CM) se comenzó a utilizar formalmente hacia principios del siglo xx, especialmente a partir de la extensión de las primeras redes de saneamiento. Posteriormente su aplicación tuvo un rol muy relevante durante las décadas de los ańos cuarenta al setenta del siglo pasado, y a partir de los años ochenta empezó a cumplir "un rol menor, muy acotado tanto en el plano de su importancia financiera global cuanto respecto del abanico de las obras beneficiadas con su limitada utilización" (Consejo de Planeamiento Urbano Ambiental [CopuA], 2006, p. 3). Cabe destacar, sin embargo, que aun en los períodos de mayor uso, la CM siempre se estableció en función del costo parcial o total de una obra pública (prorrateada por el número de beneficiarios), pero no en el recupero de la valorización inmobiliaria generada por la misma. De esta forma, la aplicación efectiva del tributo en los últimos cuarenta años fue muy heterogénea y parcial debido a las crisis socioeconómicas y políticas producidas hasta finales del año 2001. A partir de allí, la reasunción del rol del Estado como actor principal en la inversión pública implicó la ejecución de un gran volumen de obras de infraestructura, aunque la mayoría de las veces sin el correspondiente recobro a los beneficiarios, bajo el argumento de la delicada situación social heredada.

La aplicación del tributo en los municipios de la Provincia de Buenos Aires tuvo diversas regulaciones parciales durante el siglo pasado (Ordenanzas Generales 51, 140 y 143) y quedó formalmente establecido en el Decreto Ley 6769 de 1958, también llamado Ley Orgánica de las Municipalidades (Artículos 29, 60 y 106). Sin embargo, la reglamentación más completa y estructurada en materia de implementación de CM se aprobó recién en 1973, a través de la sanción de la Ordenanza General 165 de Obras Públicas Municipales. La norma cuenta con 16 secciones y 108 artículos dirigidos a regular diferentes modalidades de construcción y de recobro a través de CM de obras municipales de "pavimentación, repavimentación, cercos, veredas, urbanización, desagües pluviales y cloacales, aguas corrientes, redes de electricidad, iluminación y servicios públicos en general”.

A partir del retorno a los gobiernos democráticos en 1983, un importante número de municipios bonaerenses dictó sus propias ordenanzas locales, modificando y actualizando la disposición general de una década atrás, pero siempre basadas en ella. Asimismo, otro grupo de comunas la han mantenido vigente hasta la actualidad. De esta manera, al analizarse el conjunto de las ordenanzas municipales que rigen en la materia, se observa una serie de patrones comunes tanto en las modalidades de ejecución de las obras como en las formas de cálculo y de aplicación de los prorrateos para el cobro a los beneficiarios. ${ }^{8}$

8 Algunos documentos que analizan el financiamiento de la infraestructura y la contribución por mejoras en Argentina son Álvarez (2009); Virgolini, Giustiniani, Berén y Ganem (2007); y Del Rey y Cid (1999). 
Por último, es importante citar la aprobación, en noviembre de 2012, de la Ley Provincial 14.449 de Acceso Justo al Hábitat, que comenzó a implementarse un año después. En ella, por primera vez se articulan instrumentos de gestión del hábitat con política fiscal. En la quinta sección del capítulo iv de la norma se establece que los municipios podrán recuperar las valorizaciones inmobiliarias originadas en decisiones de carácter público, y si bien los hechos generadores apuntan más bien a los cambios normativos de usos del suelo, también prevé en el inciso e) del artículo 46 "la ejecución de obras públicas cuando no se haya utilizado para su financiación el mecanismo de contribución por mejoras".

\section{Principales características de los municipios de Berazategui y Florencio Varela}

Los dos municipios seleccionados para el estudio empírico están situados al sudeste del área metropolitana de Buenos Aires; limitan entre sí y actualmente tienen una superficie similar. Ambos tienen características netamente urbanas, media alta densidad de población, importantes tasas de crecimiento poblacional y tradicionalmente concentraron crecientes porcentajes de hogares de estratos medios bajos y bajos. A diferencia de Berazategui, Florencio Varela cuenta todavía con un porcentaje menor de población rural dedicada a actividades de agricultura intensiva (aun cuando estas actividades se encuentren en proceso de lenta reducción). De esta forma, ambas comunas son una muestra representativa de los actuales procesos de urbanización de la periferia metropolitana, sostenida en una alta demanda de suelo para sectores populares.

FIGURA I | Localización de los municipios de Berazategui y Florencio Varela en las coronas de crecimiento metropolitano

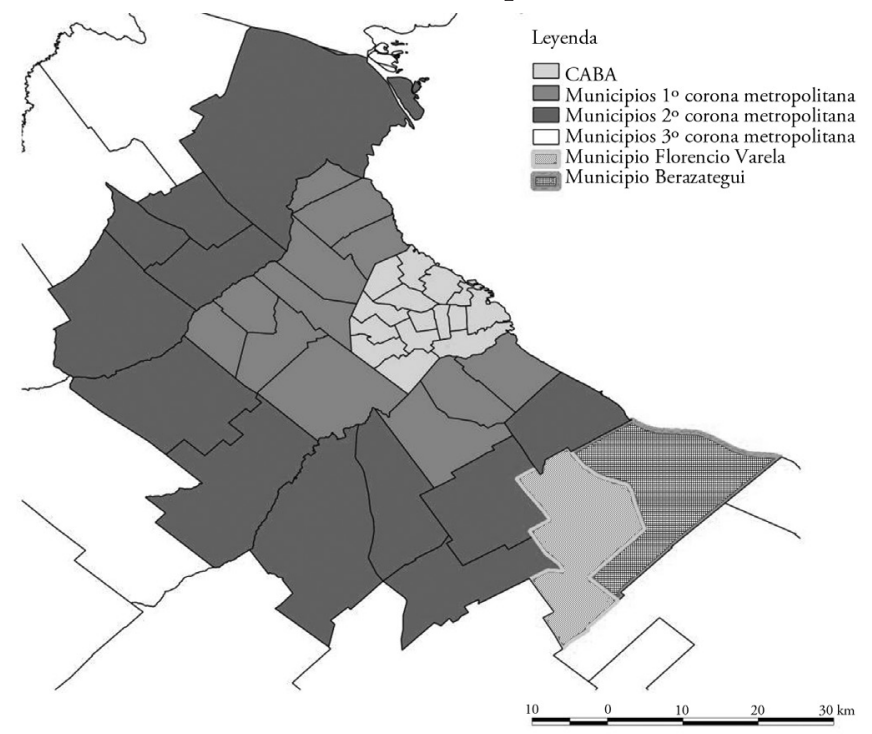

FUENTE ELABORACIÓN PROPIA CON BASE EN PLANO DE CORONAS METROPOLITANAS DEL INSTITUTO DEL CONURBANO, UNIVERSIDAD NACIONAL DE GENERAL SARMIENTO (UNGS) 
En la figura 1 se muestra la ubicación de los municipios de Berazategui y Florencio Varela en las coronas de expansión del Área Metropolitana. En la tabla 2 se observan algunos datos básicos de ambos municipios. Por último, en la tabla 3 se muestra la información censal disponible en materia de cobertura de infraestructura básica; y en la tabla 4 , los organismos que prestan cada servicio en estos municipios.

TABLA 2 | Datos básicos comparados de los municipios seleccionados, 1980-2010

\begin{tabular}{|c|c|c|c|c|c|c|c|c|}
\hline \multirow{3}{*}{$\begin{array}{c}\text { DISTRITO } \\
\text { Berazategui }\end{array}$} & \multicolumn{4}{|c|}{ POBLACIÓN (EN MILES) } & \multirow{2}{*}{\multicolumn{2}{|c|}{$\begin{array}{c}\text { VARIACIÓN } \\
\text { ABSOLUTA Y \% } \\
\text { I980-20IO }\end{array}$}} & \multirow{3}{*}{$\begin{array}{r}\begin{array}{c}\text { ÁREA } \\
(\text { KM2) }\end{array} \\
\\
188\end{array}$} & \multirow{3}{*}{$\begin{array}{c}\begin{array}{c}\text { DENSIDAD } \\
\text { BRUTA } \\
\text { (HAB/KM2) }\end{array} \\
2010 \\
1.723\end{array}$} \\
\hline & \multirow{2}{*}{$\frac{\mathbf{I 9 8 0}}{202}$} & \multirow{2}{*}{$\begin{array}{r}\text { I99I } \\
245\end{array}$} & \multirow{2}{*}{$\begin{array}{r}2001 \\
288\end{array}$} & \multirow{2}{*}{$\begin{array}{r}2010 \\
324\end{array}$} & & & & \\
\hline & & & & & 122 & $60,4 \%$ & & \\
\hline $\begin{array}{l}\text { Florencio } \\
\text { Varela }\end{array}$ & 173 & 255 & 349 & 426 & 253 & $146,2 \%$ & 190 & 2.242 \\
\hline GBA & 6.843 & 7.971 & 8.684 & 9.915 & 3.072 & $44,9 \%$ & 2.514 & 3.944 \\
\hline CABA & 2.923 & 2.965 & 2.776 & 2.891 & -32 & $-1,1 \%$ & 200 & 14.455 \\
\hline Total Амва & 9.766 & 10.936 & 11.460 & 12.806 & 3.040 & $31,1 \%$ & 2.714 & 4.719 \\
\hline
\end{tabular}

FUENTE ELABORACIÓN PROPIA CON BASE EN CENSOS NACIONALES DEL INSTITUTO NACIONAL DE ESTADÍSTICA Y CENSOS DE LA REPÚBLICA ARGENTINA (INDEC)

TABLA 3 | Hogares y disponibilidad de redes públicas de servicios, 2010

\begin{tabular}{|l|c|c|c|c|c|c|c|}
\hline \multirow{2}{*}{ MUNICIPIO } & $\begin{array}{c}\text { TOTAL } \\
\text { HOGARES }\end{array}$ & \multicolumn{2}{|c|}{$\begin{array}{c}\text { HOGARES CON } \\
\text { ACCESO A RED } \\
\text { PÚBLICA DE AGUA }\end{array}$} & \multicolumn{2}{c|}{$\begin{array}{c}\text { HOGARES CON } \\
\text { SERVICIO CLOACAL }\end{array}$} & \multicolumn{2}{c|}{$\begin{array}{c}\text { HOGARES CON } \\
\text { ACCESO A GAS POR } \\
\text { RED }\end{array}$} \\
\cline { 2 - 8 } & ABS. & ABS. & REL. & ABS. & REL. & ABS. & REL. \\
\hline Berazategui & 93.164 & 87.481 & $93,9 \%$ & 62.391 & $66,9 \%$ & 61.300 & $65,8 \%$ \\
\hline $\begin{array}{l}\text { Florencio } \\
\text { Varela }\end{array}$ & 113.135 & 102.674 & $90,7 \%$ & 30.734 & $27,2 \%$ & 49.657 & $43,9 \%$ \\
\hline
\end{tabular}

FUENTE ELABORACión PROPIA CON BASE EN INDEC, CENSO 20 IO

TABLA 4 Organismos y empresas prestadoras de servicios en municipios de Berazategui y Florencio Varela

\begin{tabular}{|c|c|c|}
\hline \multirow{2}{*}{ SERVICIO } & \multicolumn{2}{|c|}{ EMPRESA U ORGANISMO PRESTADOR DEL SERVICIO } \\
\hline & PÚBLICO & PRIVADO \\
\hline Agua y saneamiento cloacal & $\begin{array}{l}\text { Municipio (Berazategui) } \\
\text { Aguas Bonaerenses s.A. } \\
\text { (Florencio Varela) }\end{array}$ & \\
\hline Gas natural por red & & Metrogas s.A. \\
\hline Electricidad & & Edesur S.A \\
\hline $\begin{array}{l}\text { Pavimento, alumbrado y } \\
\text { desagües pluviales }\end{array}$ & Municipio & \\
\hline
\end{tabular}

FUENTE ELABORACIÓN PROPIA 


\section{Metodología y recolección de datos}

Los datos que se utilizan en este estudio fueron recolectados durante el mes de mayo de 2013 en los municipios de Berazategui y Florencio Varela. La información sistematizada abarcó el total de los terrenos baldíos en venta ubicados en las zonas urbanas y periurbanas de dichos municipios, lo cual representa un total de 580 lotes (234 en Berazategui y 346 en Florencio Varela). Es decir, los datos que se utilizan representan la población total de lotes baldíos en venta en dicha zona geográfica y momento del tiempo.

Los municipios citados fueron seleccionados por cuatros motivos: primero, porque forman parte de la segunda corona de expansión del conurbano bonaerense y, por lo tanto, constituyen casos testigo de las tensiones inmobiliarias que se producen en la ancha franja de borde rural-urbana metropolitana donde se asientan mayoritariamente los hogares de bajos recursos. Segundo, porque ambos municipios presentan una media alta proporción de lotes sin la totalidad de los servicios básicos de infraestructura, lo cual brinda la necesaria variación en la variable explicativa para estimar el impacto sobre los precios. Tercero, porque, por las razones esgrimidas más arriba, en esta región la contribución por mejoras presenta una muy baja aplicabilidad y, por ende, resulta de interés conocer cómo la provisión de infraestructura afecta los precios de los lotes. Finalmente, en los municipios seleccionados se verifican similares modelos de gestión, provisión y financiamiento de las redes de servicios, donde el rol del gobierno local es particularmente relevante.

En la figura 2 se observa la georreferenciación de los 580 lotes que se analizan en este estudio dentro del Área Metropolitana de Buenos Aires.

\section{FIGURA 2 | Localización de los registros en el Área Metropolitana de Buenos Aires}

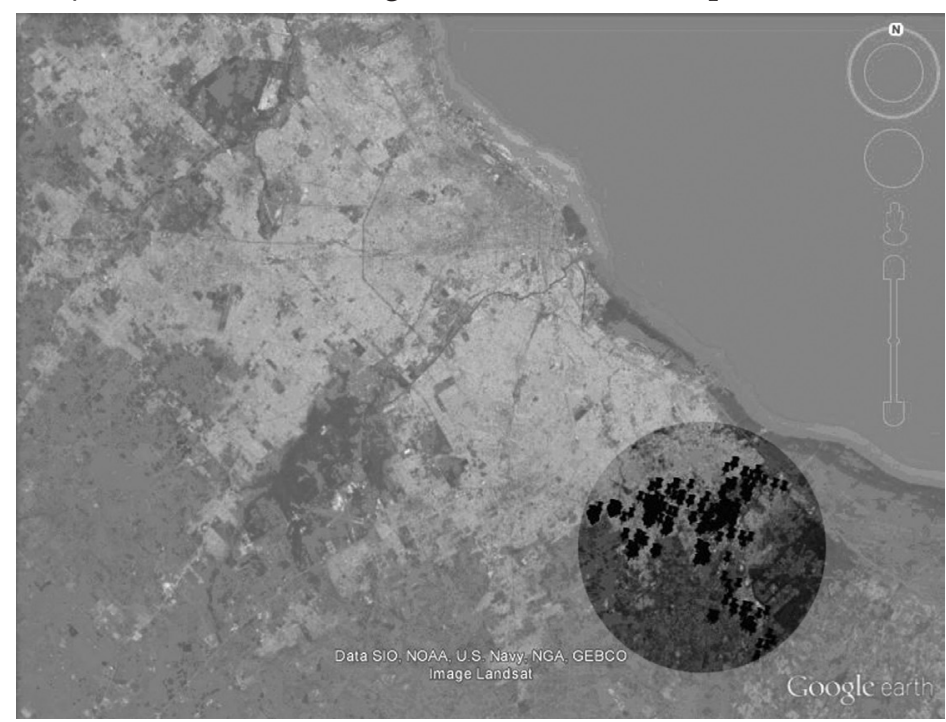

FUENTE ELABORACIÓN PROPIA CON BASE EN GOOGLE EARTH 
Como se mencionó arriba, la muestra se restringe a terrenos baldíos. Esto tiene ventajas y desventajas. Por un lado, se simplifica el análisis y se evitan problemas de medición generados por las dificultades en valuar adecuadamente el precio de una construcción. Por otro lado, se pierde la posibilidad de testear y medir la existencia de efectos heterogéneos de la provisión de infraestructura sobre el valor de la propiedad, según la existencia o no de una edificación.

Los datos se recolectaron a través del siguiente procedimiento: en primer lugar, se contactó a la empresa inmobiliaria (o propietario que vende el terreno) y se solicitó un conjunto de datos; entre ellos, el precio ofertado del lote, su superficie, el título de propiedad y la disponibilidad de servicios de infraestructura. Seguidamente, se recolectó información al pie del lote respecto a la calidad urbanística del lugar y la distancia a un conjunto de servicios (escuela, hospital, parada de colectivo, etcétera). Por último, se constató con información municipal y provincial la validez de la información recolectada respecto a superficie, disponibilidad de servicios de infraestructura y regulaciones urbanas de cada lote.

En la tabla 5 se presentan la media y el desvío estándar de las variables recolectadas. El precio promedio por metro cuadrado de los lotes es de casi 800 pesos argentinos, lo cual representa aproximadamente 150 dólares estadounidenses al tipo de cambio oficial y 115 al tipo de cambio que se utiliza en el mercado inmobiliario.

TABLA 5 | Estadísticas básicas de las variables recolectadas

\begin{tabular}{|c|c|c|}
\hline VARIABLE & MEDIA & DESVÍO ESTÁNDAR \\
\hline Precio (pesos por $\mathrm{m}^{2}$ ) & 799,4 & $1.083,8$ \\
\hline Superficie & 457,7 & 421,1 \\
\hline Cloaca $\left(S_{1}=1, N_{o}=0\right)$ & 0,429 & 0,495 \\
\hline Gas $\left(S_{1}^{\prime}=1, N_{0}=0\right)$ & 0,591 & 0,492 \\
\hline Agua $\left(S_{i}=1, N_{0}=0\right)$ & 0,960 & 0,195 \\
\hline Pavimento $\left(\mathrm{Sí}_{1}=1, \mathrm{No}=0\right)$ & 0,643 & 0,479 \\
\hline Título en condiciones óptimas $\left(S i ́=1, N_{0}=0\right)$ & 0,853 & 0,354 \\
\hline FOs (factor ocupación suelo) & 0,575 & 0,077 \\
\hline FОт (factor ocupación total) & 0,975 & 0,376 \\
\hline Densidad permitida (personas por hectárea) & 223,6 & 142,8 \\
\hline Esquina $\left(S_{1}^{\prime}=1, \mathrm{No}_{0}=0\right)$ & 0,266 & 0,442 \\
\hline Distancia avenida $(\mathrm{km})$ & 0,422 & 0,371 \\
\hline Distancia centro comercial $(\mathrm{km})$ & 1,381 & 0,922 \\
\hline Índice distancia equipamientos $(\mathrm{km})$ & 6,942 & 3,368 \\
\hline Índice calidad urbana & 0,000 & 3,287 \\
\hline Cercanía a villa miseria $\left(S_{1}=1, N_{0}=0\right)$ & 0,134 & 0,341 \\
\hline
\end{tabular}

NOTA DATOS BASADOS EN LA TOTALIDAD DE TERRENOS BALDÍOS EN VENTA EN MAYO DE $20 I 3$ EN ZONAS URBANAS Y PERIURBANAS DE LOS MUNICIPIOS DE BERAZATEGUI Y FLORENCIO VARELA. EL NÚMERO DE OBSERVACIONES ES 580.

FUENTE ELABORACIÓN PROPIA 
Puede observarse que existe una gran variación en los precios, según lo refleja el elevado desvío estándar. Esto se explica en gran medida por la localización geográfica y uso permitido del lote. En un extremo, los lotes zonificados como "céntricos" tienen un valor promedio de $4.360 \$ / \mathrm{m}^{2}$, mientras que en el otro extremo, los lotes ubicados en la franja periurbana, zonificados como "agropecuarios intensivos", tienen un valor promedio de $62 \$ / \mathrm{m}^{2}$. Respecto a la superficie, el tamańo promedio de los lotes es de $458 \mathrm{~m}^{2}$; y nuevamente hay alta variación, con lotes ubicados en zonas céntricas que tienen un mínimo de $150 \mathrm{~m}^{2}$ y lotes ubicados en la periférica que llegan a los $3.600 \mathrm{~m}^{2}$.

La gran mayoría de los lotes dispone de servicio de agua por red (96\%), pero la disponibilidad de cloacas (43\%), gas en red (59\%) y calles pavimentadas $(64 \%)$ es sustancialmente inferior. El $85 \%$ de los lotes tiene el título en condiciones óptimas ${ }^{9}$ y el $27 \%$ se encuentra ubicado en una esquina.

Respecto a las normativas urbanas vigentes, el fos (o Factor de Ocupación del Suelo) promedio en la muestra es de 0,575 . Esta variable indica el ratio máximo permitido por las reglamentaciones locales entre la superficie de planta edificada y la superficie del lote. Por otra parte, el valor promedio del ғот (о Factor de Ocupación Total, que establece el ratio máximo entre el total de la superficie edificada y la del lote) es de 0,975; y el valor promedio de la máxima densidad permitida es de 224 habitantes por hectárea. Asimismo, las normativas determinan los usos del suelo permitidos. La muestra recolectada incluye trece tipos de zonas diferentes, que se pueden agrupar en cinco grandes categorías: (i) residencial (incluye al 58,5\% de los lotes); (ii) industrial (34,6\%); (iii) banda de circulación (3,1\%); (iv) centro $(2,4 \%)$; y (v) agropecuaria intensiva $(1,4 \%)$.

La distancia promedio al centro comercial es de 1,3 kilómetros en la muestra, y el $13 \%$ de los lotes se encuentra a menos de 1 kilómetro de un asentamiento informal. Con base en la información recolectada sobre distancia desde el lote a una escuela pública, un centro de salud u hospital, una comisaria, un espacio verde y la parada de transporte más cercana, se creó un Índice de Distancia a Equipamientos (definido como la suma de la distancia a estos cinco equipamientos), que tiene un valor promedio de 7 kilómetros. Finalmente, se creó un Índice de Calidad Urbana, definido como la suma del valor estandarizado de cinco atributos relevados del entorno del lote (arboleda, veredas, mantenimiento de la calle, presencia de basurales y riesgo de anegamiento).

Adicionalmente a lo anterior, y a efectos de su posterior análisis comparativo, se calcularon los costos de construcción de las diferentes redes de infraestructura en los municipios del sector sur metropolitano, entre los cuales se localizan Berazategui y Florencio Varela. Tal cálculo se realizó sobre la base de un proyecto prototipo de urbanización de 200 lotes de $250 \mathrm{~m}^{2}$ de área cada uno que no requería rellenos

9 La variable merece dos comentarios. Primero, se incluyen en la categoría de "no tiene título en condiciones óptimas" a los lotes en los cuales el propietario solo dispone de boleto de compraventa, acta Ley 24.374, o derechos posesorios. Segundo, si bien existe la ocupación ilegal de tierras en estos municipios, la muestra no incluye ningún lote ocupado ilegalmente, debido a que la recolección de datos se restringió a terrenos baldíos, es decir, deshabitados. De esta forma, los lotes relevados se encuentran jurídica, técnica y catastralmente conformados. 
y/o movimientos de suelo especiales. En la tabla 6 se muestran los resultados de los cálculos del costo directos y final de ejecución de cada red por lote y el final resultante por $\mathrm{m}^{2}$ de lote.

TABLA 6 Costo por $\mathrm{m}^{2}$ de las redes de servicio

\begin{tabular}{|l|c|c|c|c|}
\hline \multicolumn{1}{|c|}{ SERVICIO } & $\begin{array}{c}\text { COSTO DIRECTO } \\
\text { POR LOTE, EN } \\
\text { \$ ARGENTINOS }\end{array}$ & $\begin{array}{c}\text { COSTO FINAL } \\
\text { POR LOTE, EN } \\
\text { \$ ARGENTINOS }\end{array}$ & $\begin{array}{c}\text { COSTO FINAL / } \\
\text { M2 DE LOTE, EN } \\
\text { \$ ARGENTINOS }\end{array}$ & $\begin{array}{c}\text { COSTO FINAL / } \\
\text { M2 DE LOTE, } \\
\text { EN US\$ }\end{array}$ \\
\hline Agua & $1.503,0$ & $2.269,5$ & 9,1 & 1,6 \\
\hline Cloaca & $5.360,4$ & $8.094,2$ & 32,4 & 5,8 \\
\hline Pavimento & $9.090,0$ & $13.725,9$ & 54,9 & 9,8 \\
\hline Red eléctrica y alumbrado & $1.438,2$ & $2.171,7$ & 8,7 & 1,6 \\
\hline Red gas & $1.843,2$ & $2.783,2$ & 11,1 & 2,0 \\
\hline
\end{tabular}

FUENTE ELABORACIÓN PROPIA

\section{Resultados obtenidos}

En función de los objetivos del estudio, la presente sección tiene dos finalidades: primero, presentar mediciones del impacto que tiene la provisión de infraestructura sobre el precio del terreno utilizando diferentes métodos, y analizar cómo varían dichos efectos dependiendo de algunas características del terreno, como, por ejemplo, la cercanía al centro comercial. ${ }^{10}$ Segundo, analizar las ventajas y desventajas de las distintas metodologías y su potencial uso como método para la implementación efectiva del instrumento de contribución por mejoras.

En la fila 1 de la tabla 7 se presentan los resultados del método más sencillo de medición, que es simplemente la diferencia en el precio promedio por metro cuadrado $\left(\$ / \mathrm{m}^{2}\right)$ de los lotes con y sin servicios de infraestructura. Como se observa, el precio promedio de los lotes con desagües cloacales resultó ser de $1.269 \$ / \mathrm{m}^{2}$, mientras que el precio de los lotes sin este servicio es de $447 \$ / \mathrm{m}^{2}$. Esto supone una diferencia de $822 \$ / \mathrm{m}^{2}$ o del $184 \%$. La diferencia resulta ser algo menor para los servicios de gas, pavimento y agua corriente, pero en todos los casos más que duplica el precio de los lotes sin provisión de dichos servicios.

10 Cabe señalar que existe una literatura empírica que mide el impacto de la provisión de servicios de infraestructura sobre el precio de la propiedad, pero la misma se concentra mayoritariamente en países desarrollados. Para América Latina, algunos de los trabajos realizados son Monkkonen y Ronconi (2013); Naranjo y Janive (2013); Ronconi, Casazza, Monkkonen y Reese (2012); y Serra, Dowall, Motta y Donovan (2004). Otros trabajos relevantes son: Álvarez (2009); Borrero Ochoa (2011); Catenazzi (2013); Cuenya Pupareli, Mosto, Cascella, Brunstein y Di Loreto (2003); Esteban (2007); Furtado y Acosta (2013); Maldonado Copello y Smolka (2003); y Vetter, Massena y Vetter (2011). Una completa revisión de la literatura se encuentra en Smolka (2013). 
TABLA 7 Diferencia (absoluta y porcentual) entre lotes con y sin infraestructura

\begin{tabular}{|l|c|c|c|c|}
\hline \multicolumn{1}{|c|}{ VARIABLE } & CLOACA & GAS & AGUA & PAVIMENTO \\
\hline Precio por $\mathrm{m}^{2}$ (dif. absoluta) & $\$ 822$ & $\$ 648$ & $\$ 472$ & $\$ 567$ \\
\hline Precio por $\mathrm{m}^{2}$ (dif. porcentual) & $184 \%$ & $156 \%$ & $136 \%$ & $130 \%$ \\
\hline Zonificación residencial & $23 \%$ & $38 \%$ & $5 \%$ & $73 \%$ \\
\hline Distancia centro comercial & $-27 \%$ & $-22 \%$ & $-25 \%$ & $-40 \%$ \\
\hline Título de propiedad & $11 \%$ & $3 \%$ & $109 \%$ & $22 \%$ \\
\hline Fot permitido & $30 \%$ & $39 \%$ & $52 \%$ & $29 \%$ \\
\hline Densidad permitida & $94 \%$ & $82 \%$ & $76 \%$ & $57 \%$ \\
\hline Disponibilidad infraestructura & $75 \%$ & $91 \%$ & $466 \%$ & $77 \%$ \\
\hline Riesgo de anegamiento & $-63 \%$ & $-66 \%$ & $50 \%$ & $-34 \%$ \\
\hline Cercanía a basural & $-67 \%$ & $-46 \%$ & $0 \%$ & $-78 \%$ \\
\hline
\end{tabular}

FUENTE ELABORACIÓN PROPIA

Este método sobrestima en gran medida el impacto real que tiene la provisión de infraestructura sobre el precio. La causa es que los lotes con un determinado servicio de infraestructura tienen, además, un conjunto de atributos diferentes (y positivos) respecto de los lotes sin servicio, que los hacen más valorados en el mercado. Por ejemplo, los lotes con cloaca (respecto a los lotes sin cloaca) están ubicados más cerca del centro comercial, son más propensos a ser zonificados como residenciales, a tener un mayor FOT, una mayor densidad permitida, a tener el título de propiedad en correctas condiciones, a tener menor riesgo de anegamiento, a estar más alejados de basurales y a disponer de otros servicios de infraestructura. ${ }^{11}$ Un fenómeno similar se observa al analizar las diferentes características de los lotes con y sin gas, agua corriente y/o pavimento. Estos resultados indican la necesidad e importancia de realizar un análisis multivariado.

La ecuación (1) presenta una versión simple del modelo estadístico que se utiliza para estimar el impacto de cada servicio de infraestructura sobre el precio:

(1) Precio/m ${ }_{i}^{2}=\beta$ Infraestructura $i+\delta \boldsymbol{X}_{i}+\varepsilon_{i}$

Donde la variable dependiente $\log \left(\text { Precio/ } \mathrm{m}^{2}\right)_{i}$ es el precio de la tierra por metro cuadrado del lote $i$; Infraestructura es una variable dicotómica ( 1 si tiene, 0 si no tiene) referida a los siguientes servicios: agua corriente, gas en red, cloacas y pavimentación; X es un vector de variables de control. El objetivo principal es estimar los coeficientes $\beta$. Todos los modelos se estiman con la técnica de Mínimos Cuadrados Ordinarios (ols) con errores estándar robustos.

11 La variable disponibilidad de infraestructura mide la cantidad de servicios que tienen los lotes excluyendo el que se analiza en cada columna. Por ejemplo, en el caso de lotes con y sin cloaca, la variable considera si los lotes tienen agua corriente, gas, y pavimento. El valor de $75 \%$ resulta del hecho de que, en promedio, los lotes con cloaca tienen 2,8 de los otros 3 servicios mencionados, mientras que los lotes sin cloaca tienen solo 1,6; y, por ende, la diferencia es del $75 \%$ a favor de los lotes con cloaca. 
Los resultados se presentan en la tabla 8 , que resulta conveniente explicar, ya que se encuentra organizada de una forma un tanto atípica. Por un lado, cada celda del cuadro resulta de estimar un modelo estadístico diferente. Los 16 estimadores se obtienen de correr 16 regresiones diferentes que varían según el servicio de infraestructura que se analiza (filas) y los controles que se incluyen (columnas). Por otro lado, cada valor que se reporta indica el impacto estimado que tiene la provisión del servicio de infraestructura indicado al comienzo de la fila sobre el precio por $\mathrm{m}^{2}$. En negrita se indican los estimadores que son estadísticamente significativos al $10 \%$.

El primer modelo que se estima (columna 1) solo incluye como variables explicativas la provisión de infraestructura y un conjunto de 13 indicadores referidos a las reglamentaciones urbanísticas o códigos de zonificación vigentes en los municipios. La inclusión de efectos fijos por zonificación implica que la estimación se obtiene de comparar el precio de los lotes con y sin infraestructura que están categorizados con el mismo tipo de zona urbanística. Este es un paso fundamental, ya que sirve de poco comparar el precio de un lote con servicio categorizado como residencial con un lote sin servicio categorizado como industrial.

TABLA 8 Efecto de la provisión de infraestructura sobre el precio del terreno (medido en pesos argentinos por $\mathbf{m}^{2}$ )

\begin{tabular}{|l|r|r|r|c|}
\cline { 2 - 5 } \multicolumn{1}{c|}{} & (I) & (2) & (3) & (4) \\
\hline Cloaca & 437,6 & 281,8 & 112,6 & 95,7 \\
\hline Gas & 269,7 & 149,0 & 29,5 & 31,5 \\
\hline Agua & 179,0 & 81,6 & 107,4 & 70,7 \\
\hline Pavimento & 342,4 & 247,0 & 77,1 & 61,3 \\
\hline Zonificación & Sí & Sí & Sí & Si \\
\hline FOs, FOT, densidad permitida & No & Sí & Sí & Sí \\
\hline $\begin{array}{l}\text { Distancia centro comercial, disponibilidad otra } \\
\text { infraestructura, distancia a infraestructura }\end{array}$ & No & No & Sí & Sí \\
\hline $\begin{array}{l}\text { Calidad urbana, distancia a servicios, barrio } \\
\text { informal y título }\end{array}$ & No & No & No & Sí \\
\hline
\end{tabular}

NOTA EL NÚMERO DE OBSERVACIONES ES DE 580 LOTES. CADA CELDA SE OBTIENE CON UN MODELO DIFERENTE, E INDICA EL IMPACTO DEL SERVICIO DE INFRAESTRUCTURA SOBRE EL PRECIO POR METROS CUADRADO POR LOTE. LA VARIABLE DEPENDIENTE ES EL LOG (PRECIO POR M⿻丷木) Y LA PRINCIPAL VARIABLE EXPLICATIVA ES UN INDICADOR DE LA DISPONIBILIDAD DE SERVICIOS DE INFRAESTRUCTURA. EN NEGRITA SE INDICAN LOS ESTIMADORES QUE SON ESTADÍSTICAMENTE SIGNIFICATIVOS AL O,OI, O,OS O O, IO POR CIENTO.

FUENTE ELABORACIÓN PROPIA

En la columna 2 se agregan al modelo anterior las variables FOs, FOT y densidad habitacional permitida. Tal como se mostró en la tabla 7, los lotes con servicio de infraestructura en general tienen regulaciones más flexibles (es decir, mayor FOS, FOT y densidad), lo cual es de esperar que redunde en mayores precios $y$, por ende, que los nuevos estimadores sean sustancialmente menores. Los resultados indican que, efectivamente, tanto las mediciones basadas en la diferencia simple entre lotes con y sin servicio, como el modelo de la columna 1 , sufren el problema de variable omitida. 
Los nuevos estimadores son sustancialmente menores. Por ejemplo, para el caso del servicio de cloacas, la diferencia simple de precios entre lotes con/sin servicio (como se observó más arriba) es de $822 \$ / \mathrm{m}^{2}$, mientras que de acuerdo al modelo de la columna 2, la diferencia es de $282 \$ / \mathrm{m}^{2}$. Para los servicios de agua, gas y pavimento, las diferencias resultaron ser, respectivamente, de $149 \$ / \mathrm{m}^{2}, 82 \$ / \mathrm{m}^{2}$ y $247 \$ / \mathrm{m}^{2}$.

En la columna 3 se agregan tres variables adicionales: distancia al centro comercial, disponibilidad de otros servicios de infraestructura y cercanía a la infraestructura (se define abajo). La motivación para incluir las dos primeras variables es el problema arriba mencionado de variables omitidas. Los lotes con un determinado servicio de infraestructura tienden, además, a disponer de otros servicios y a estar ubicados más cerca del centro comercial. Nuevamente, la inclusión de estos controles adicionales es de esperar que redunde en estimadores de menor magnitud.

Por otro lado, la tercera variable (cercanía a la infraestructura) se incluye para enfrentar lo que en la jerga econométrica se conoce como "problema de contaminación". La idea es que cuando un determinado lote recibe un servicio de infraestructura, no solo se ve afectado positivamente su propio precio, sino que también es posible que afecte positivamente el precio de un lote vecino, aun cuando el mismo no reciba el servicio. Es decir, el "tratamiento" que recibe el lote i afecta su precio y también el precio del lote de "comparación” j, con lo cual el diferencial de precios entre ambos lotes tiende a subestimar el efecto real de la provisión de infraestructura.

La forma en que se intenta enfrentar el problema de contaminación es a través de incluir la variable "cercanía a infraestructura", que mide la distancia al servicio de infraestructura en cuestión. Por ejemplo, en el modelo de la fila 1, columna 3, esta variable adopta un valor 0 para los lotes que disponen del servicio de cloacas, y para los restantes lotes es igual a la distancia a la red de cloacas más cercana.

La inclusión de esta variable, si bien podría, al menos parcialmente, solucionar el problema de "contaminación", puede generar un problema de multicolinealidad, ya que -como se aprecia- por su misma definición hace que esté correlacionada con la principal variable explicativa (es decir, infraestructura).

Los resultados de la columna 3 son sustancialmente menores que los de la columna 2. La diferencia de precios entre lotes con y sin servicio es de $113 \$ / \mathrm{m}^{2}$ para cloacas, $30 \$ / \mathrm{m}^{2}$ para gas, $107 \$ / \mathrm{m}^{2}$ para agua y $77 \$ / \mathrm{m}^{2}$ para pavimento. ¿Esta importante reducción se debe a que el nuevo modelo soluciona problemas de variable omitida, o a que introduce problemas de multicolinealidad? Luego de realizar un análisis de "factor de inflación de la varianza" (es decir, vif o variance inflation factor), la respuesta es que la reducción se explica principalmente por el problema de variables omitidas. ${ }^{12}$ Adicionalmente, merece destacarse el elevado poder explicativo de estos modelos en la medida que el R-cuadrado varía entre 0,60 y 0,65.

12 Se computó el vif y en tres de los cuatro modelos resultó inferior al valor de 5 (que usualmente se considera como el piso mínimo a partir del cual se considera que hay un problema de multicolinealidad). En el único caso en que vif adopta un valor superior a 5 es con el gas, donde resulta ser de 6,58. Sin embargo, al excluir la variable distancia a gas-que es la que produce el problema de multicolinealidad-, el coeficiente de interés es muy similar al que se presenta en la tabla. 
Por último, en la columna 4 se incluye un conjunto amplio de controles adicionales que reflejan otras características del terreno (si el dueño posee el título de propiedad, si el lote se ubica en una esquina), distancia a servicios (escuela, hospital, transporte público, comisaría, espacio verde) y calidad de la urbanización y calidad ambiental del entorno inmediato donde se ubica el lote (cercanía a basurales, riesgo de anegamiento, veredas, arbolado, presencia de equipamientos o comercios molestos). La presentación de este modelo por separado responde al interés por analizar la sensibilidad de los resultados a la inclusión de controles que no son de tan fácil acceso para la autoridad pública, como las variables incluidas en los primeros tres modelos. Es decir, si el poder público intenta medir el impacto de la provisión de infraestructura sobre el precio utilizando solo la información del lote que tiene fácilmente disponible (zonificación, FOT, FOs, densidad, distancia al centro comercial y disponibilidad de otros servicios), ¿`sufrirán los estimadores del problema de variable omitida? ¿Los resultados serán muy diferentes a los que obtendría con un modelo más complejo, que controle por otras características del terreno, como título de propiedad, distancia a servicios y calidad urbana?

La comparación entre las columnas 3 y 4 indica cambios en los coeficientes que van desde menos de un $10 \%$, en el caso de gas, hasta poco más de un tercio en el caso del agua. ${ }^{13}$ Esto sugiere que un análisis multivariado que no incluya un conjunto amplio de atributos del terreno, como cercanía a diversos servicios públicos y calidad del entorno urbano, puede resultar en estimadores sesgados.

Si bien no es el objetivo central de este trabajo analizar el impacto que tienen sobre el precio del lote la normativa urbana, su ubicación geográfica, distancia al centro comercial, calidad del entorno urbano y otros atributos del lote, cabe mencionarlos para el lector interesado. Los estimadores indican que el precio del lote es más elevado cuando tiene regulaciones más flexibles (mayor FOT, FOS y densidad); está ubicado más cerca del centro comercial y de otros servicios; tiene un entorno urbano de mayor calidad; y dispone de título de propiedad. Todos estos resultados son los que la teoría sugiere.

Habiendo computado estimadores de impacto a través de diferentes especificaciones, se procede ahora a analizar cómo varían los mismos según la cercanía del terreno al área central de la localidad. En las figuras 3 a 6 se presentan los resultados obtenidos al incluir al modelo de la tercera columna, un término de interacción entre el servicio de infraestructura y la distancia al área central. ${ }^{14}$ Con una línea sólida se indican los coeficientes estimados, y con líneas punteadas el intervalo de 95\% de confianza. En el eje vertical se presenta el impacto (medido como pesos $/ \mathrm{m}^{2}$ ) y en el eje horizontal la distancia al centro comercial (medida en cuadras).

Se observa que, para los cuatro servicios analizados, los efectos son mayores cuanto más cerca del área central se encuentra ubicado el terreno. La magnitud de la diferencia es considerable. Por ejemplo, un terreno ubicado en el mismo centro

13 La incorporación de estas variables adicionales genera un problema de multicolinealidad en el modelo donde la variable dependiente es pavimento, por lo cual se excluye la variable distancia a pavimento de la regresión.

14 Para tener mayor flexibilidad se agrega también la interacción entre el servicio de infraestructura y la distancia al área central elevada al cuadrado. 
comercial tiene un incremento en el precio por $\mathrm{m}^{2}$ al recibir servicios de cloacas de 376 pesos, mientras que el efecto es de solo 113 pesos si se ubica a 1 kilómetro del área central. Para los restantes servicios las diferencias son también de magnitud, aunque un poco menores. Estos resultados resaltan la necesidad de considerar la localización del lote al momento de analizar el impacto que tiene la infraestructura sobre los precios.

\section{FIGURA 3 |}

Efecto de cloacas sobre precio/ $\mathrm{m}^{2}$ distancia al área central

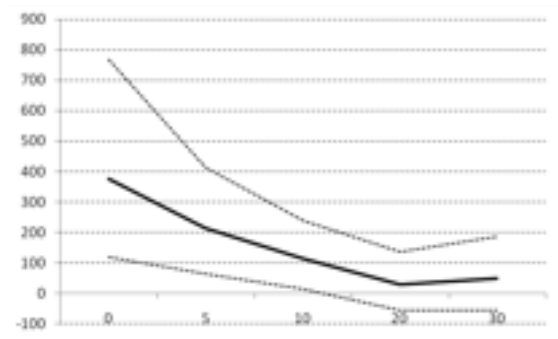

FUENTE ELABORACIÓN PROPIA

FIGURA 5

Efecto del agua sobre precio/ $/ \mathrm{m}^{2}$ según distancia al área central

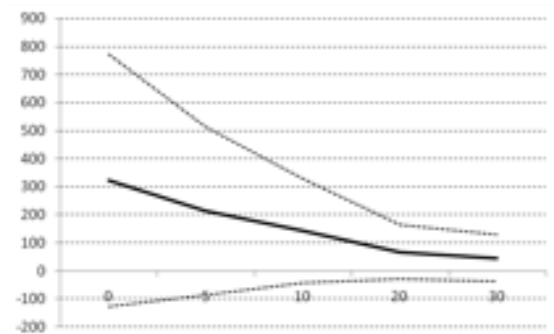

FIGURA 4 |

\section{Efecto del gas sobre precio $/ \mathrm{m}^{2}$ según distancia al área central}

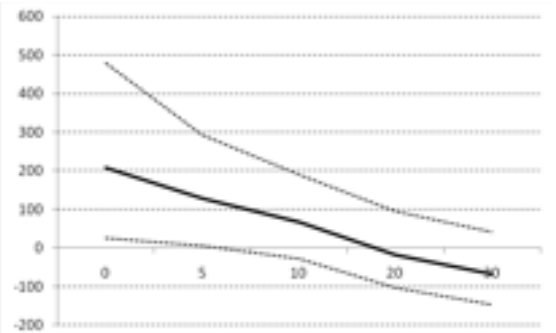

\section{FIGURA 6 |}

Efecto del pavimento sobre precio/ $\mathrm{m}^{2}$ según distancia al área central

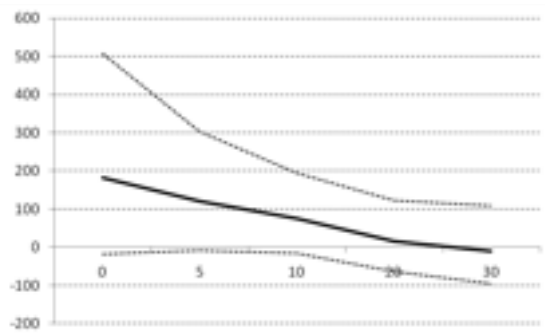

FUENTE ELABORACIÓN PROPIA

Por último, se realizó una comparación entre los estimadores de impacto sobre los precios (utilizando el modelo más completo de la columna 4 de la tabla) con el costo de construcción de las redes de servicios de infraestructura. El resultado se observa en la tabla 9.

La comparación sugiere que el costo de la provisión de infraestructura es sustancialmente menor al incremento promedio en el precio del terreno. Teniendo en cuenta que en la práctica los propietarios del terreno solo pagan una porción del costo de la construcción, resulta evidente la necesidad de darle un mayor uso al concepto de contribución por mejora. 
TABLA 9 Incidencia de las redes de infraestructura en la valorización del suelo y comparación con el costo final de ejecución de las obras

\begin{tabular}{|l|c|c|c|}
\hline $\begin{array}{c}\text { RED DE } \\
\text { INFRAESTRUCTURA }\end{array}$ & $\begin{array}{c}\text { VALORIZACIÓN DEL } \\
\text { SUELO PROMEDIO } \\
\left(\mathbf{E N ~ \$ ~ P O R ~ M ~}^{2}\right)\end{array}$ & $\begin{array}{c}\text { COSTO FINAL DE } \\
\text { CONSTRUCCIÓN } \\
\left(\text { EN \$ POR M }^{2}\right)\end{array}$ & $\begin{array}{c}\text { DIFERENCIA ENTRE } \\
\text { VALORIZACIÓN Y COSTO } \\
\text { DE CONSTRUCCIÓN } \\
\left(\text { EN \$ POR M }^{2}\right)\end{array}$ \\
\hline Red de cloacas & 95,7 & 32,4 & 63,3 \\
\hline Red de gas natural & 31,5 & 11,1 & 20,4 \\
\hline Red de agua potable & 70,7 & 9,1 & 61,6 \\
\hline Pavimento $^{*}$ & 61,3 & 54,9 & 6,4 \\
\hline
\end{tabular}

NOTA $\left(^{*}\right.$ ) EN LA TABLA SE INCLUYÓ, PARA SU COMPARACIÓN, UN TIPO DE PAVIMENTACiÓN (PAVIMENTO DE CONCRETO ASFÁLTICO SIN CORDÓN CUNETA Y DESAGÜE SUPERFICIAL), EN LA MEDIDA EN QUE LA GRAN MAYORÍA DE LOS LOTES RELEVADOS SE UBICAN EN BARRIOS QUE CUENTAN CON UN SERVICIO DE SIMILARES CARACTERÍSTICAS CONSTRUCTIVAS.

FUENTE ELABORACIÓN PROPIA

\section{Conclusiones}

El estudio muestra empíricamente que las infraestructuras para los servicios públicos en red tienen un impacto positivo sobre el valor de mercado de la tierra, y que dicho efecto es mayor cuanto más cerca del centro comercial se ubica el terreno. Estos impactos sobre el precio son mucho mayores que lo que en la práctica el poder público recobra a los propietarios.

Desde el punto de vista metodológico, el documento analiza las fortalezas y debilidades de "mínimos cuadrados con datos cross-section" como instrumento de medición de la plusvalía generada por la provisión de infraestructura pública. Los resultados sugieren, por un lado, que el método brinda grandes beneficios respecto a la práctica más sencilla de comparar el precio de lotes con y sin servicio. Esto se debe a que los lotes con servicio suelen tener un conjunto amplio de características adicionales a la infraestructura que los hacen más valorados en el mercado. Segundo, y vinculado al punto anterior, aparece como necesario recolectar gran cantidad de información sobre los atributos del terreno. Sin información detallada sobre las normas que regulan al lote, su cercanía a un conjunto amplio de servicios y la calidad urbana del lugar donde se encuentra el lote, es muy posible que resulten estimadores sesgados del impacto de la infraestructura sobre el precio.

Los análisis indican que existe una importante diferencia positiva entre el impacto sobre el precio del suelo y el costo de construcción de las redes de servicios de infraestructura (aunque menor en el caso del pavimento). Sin embargo, y a pesar de esto, en Buenos Aires -y en Argentina en general- se utiliza muy limitadamente en la práctica la contribución por mejoras; y en los pocos casos en que se utiliza, se establece en función del costo parcial o total de la obra pública (prorrateado por el número de beneficiarios), pero no en el recupero de la valorización inmobiliaria generada por la misma. Esto es una deficiencia, ya que dicho instrumento es conceptualmente de utilidad para financiar la inversión en infraestructura pública, y fundamentalmente para distribuir equitativamente los costos de la misma. 
La contribución de mejoras ( $\mathrm{CM}$ ) es la imposición tributaria de orden municipal más afectada por las condiciones socioeconómicas de la población. Su forma de determinación y de aplicación está siendo revisada en un buen número de municipios. Como se dijo, en la Argentina, la CM fue una herramienta de cierto uso hasta mediados de los años ochenta del siglo pasado (aunque siempre en función del costo de la obra pública, nunca en función de la valorización inmobiliaria), y durante ese período se diseñaron las legislaciones regulatorias de los gobiernos locales que perduran hasta la actualidad. Las sucesivas crisis sociopolíticas posteriores provocaron una paulatina retracción de su aplicación. Como efecto de esto, en el transcurso de los últimos años la obra pública de servicios fue afrontada mayoritariamente por fondos públicos coparticipados (o a través de subsidios) desde el ámbito nacional y provincial, que en la casi totalidad de los casos no aplicaron dispositivos de recuperación.

Si bien la posibilidad de aplicar la см considerando la valorización del inmueble está prevista en la provincia de Buenos Aires (Ley Provincial de Acceso Justo al Hábitat No. 14.449 del ańo 2013), ciertamente hay dificultades en su aplicación, que en el caso argentino están asociadas a descalces entre los costos de obra y los cálculos de recobro por efectos de procesos inflacionarios; falta de capacidades técnicas en las estructuras municipales para realizar los cálculos del tributo; y el diseño de la aplicación de la CM, que no tiene en cuenta ni la valorización ni la capacidad contributiva aparente de cada inmueble. A pesar de estos inconvenientes, la CM constituye una útil herramienta de financiamiento de las obras que no está siendo aprovechada.

\section{Agradecimientos}

Paulo Barbieri, Gastón Damián Gandini y Margarita Troncoso brindaron excelente asistencia de investigación. Colaboraron en la recolección de datos: Martín Babuín, Gustavo Damián Ferreyra, Tomás Alejandro Cappeletti, Víctor Emmanuel Ramírez, Daniela Barbera y Martín de Alzaga. Este proyecto no hubiera sido posible sin el apoyo del Lincoln Institute.

\section{Referencias bibliográficas}

Álvarez, R. (2009). Contribución de mejoras en Argentina. Casos de Rosario, Córdoba y Santa Fe. Trabajo presentado en el Primer Congreso Latinoamericano de Valorización, Bogotá, Colombia, del 11 al 12 de marzo de 2009.

Baer, L. \& Kauw, M. (2016). Mercado inmobiliario y acceso a la vivienda formal en la Ciudad de Buenos Aires, y su contexto metropolitano, entre 2003 y 2013. EURE, 42(126), 5-25. http://dx.doi.org/10.4067/S0250-71612016000200001

Borrero Ochoa, O. (2011). Betterment levy in Colombia: Relevance, procedures, and social acceptability. Land Lines, 23(2), 14-19. http://www.lincolninst.edu/publications/ articles/betterment-levy-colombia 
Catenazzi, A. (2013). Las redes de agua y saneamiento en la agenda urbana: encuentros y desencuentros. En J. Erazo Espinosa (comp.), Infraestructuras urbanas en América Latina: gestión y construcción de servicios y obra pública (pp. 117-138). Quito: Instituto de Altos Estudios Nacionales (IAEN). http://bit.ly/2h7qdPS

Consejo de Planeamiento Urbano Ambiental (COPUA). (2006). Instrumentos económicos para la gestión del suelo. Programa "Urbe y Tributación". Plan Urbano Ambiental de la Ciudad de Buenos Aires. Mimeo.

Cuenya, B., Pupareli S., Mosto G., Cascella, Brunstein \& Di Loreto, M. (2003). Relevamiento de métodos e instrumentos para la ponderación y recuperación de plusvalías urbanas generadas por la acción pública municipal. Buenos Aires: Consejo Nacional de Investigaciones Científicas y Técnicas (Conicet).

Del Rey, E. \& Cid, J. C. (2004). La contribución de mejoras: una aplicación de econometría espacial. Trabajo presentado en la XXXVIII Reunión anual de la Asociación Argentina de Economía Política, Universidad Nacional de Cuyo. http://www.aaep.org.ar/anales/ works/works2003/delRey_Cid.pdf

Esteban, R. (2007). Consorcio parque náutico San Fernando: concesión de tierras municipales y recuperación de plusvalías. En M. C. Vejarano (ed.), Movilización social de la valorización de la tierra: casos latinoamericanos (pp. 33-54). Cambridge, MA: Lincoln Institute of Land Policy. http://bit.ly/2xRjwnY

Furtado, F. \& Acosta, C. (2013). Recuperación de plusvalías urbanas en Brasil, Colombia y otros países de América Latina: legislación, instrumentos e implementación. Working Paper. Cambridge, Ma: Lincoln Institute of Land Policy.

Instituto Nacional de Estadística y Censos (IndeC), República Argentina (2010). Censo Nacional de Población, Hogares y Viviendas 2010. http://bit.ly/2h7LHMG

Macón, J. (1972). Financiación pública por contribución de mejoras. Buenos Aires: Consejo Federal de Inversiones.

Maldonado Copello, M. \& Smolka, M. (2003). Using value capture to benefit the poor: The Usme project in Colombia. Land Lines, 15(3), 15-17.

Marienhoff, M. (1975). Tratado de Derecho Administrativo. Tomo III. Buenos Aires: Editorial Abeledo-Perrot.

Monkkonen, P. \& Ronconi, L. (2013). Land use regulations, compliance and land markets in Argentina. Urban Studies, 50(10), 1951-1969. http://bit.ly/2yoeJ1D

Naranjo, V. \& Janive, D. (2013). The impact of bus rapid transit system on land prices in Mexico City. Working Paper. Cambridge, Ma: Lincoln Institute of Land Policy.

Ronconi, L., Casazza, J., Monkkonen, P. \& Reese, E. (2012). Análisis de las características del funcionamiento del mercado de suelo en tres ciudades de la Argentina: Buenos Aires, Córdoba y Rosario. Documento de Trabajo 9. Buenos Aires: Centro de Investigación y Acción Social (cias). http://bit.ly/2h8k2Lz

Serra, M. V., Dowall, D., Motta, D. \& Donovan, D. (2004). Urban land markets and urban land development: An examination of three Brazilian cities: Brasília, Curitiba and Recife. Institute of Urban and Regional Development. Working Paper 2004-3. University of California Berkeley.

Smolka, M. (2013). Implementing value capture in Latin America. Policies and tools for urban development. Policy Focus Report. Cambridge, MA: Lincoln Institute of Land Policy. http://bit.ly/2zeILnK 
Smolka M. \& Amborski, D. (2003). Recuperación de plusvalías para el desarrollo urbano: una comparación inter-americana. EURE, 29(88), 55-77. http://dx.doi.org/10.4067/ S0250-71612003008800003

Torres, H. (1993).El mapa social de Buenos Aires (1940-1990). Serie Difusión 3, Facultad de Arquitectura, Diseńo y Urbanismo de la Universidad de Buenos Aires.

Torres, H. (2001). Cambios socioterritoriales en Buenos Aires durante la década de 1990. EURE, 27(80), 33-56. http://dx.doi.org/10.4067/S0250-71612001008000003

Vetter, D., Massena, R. M. \& Vetter, M. F. (2011). Land values and the affordability of lower income housing: Three municipalities in the Rio de Janeiro metropolitan region. Río de Janeiro: Mimeo.

Virgolini, E.,Giustiniani, P., Berén, T. \& Ganem, J. (2007). Instrumentos de captura de valor en municipios. El caso de la municipalidad de Rosario desde 1990. Trabajo presentado en las Duodécimas Jornadas en la Facultad de Ciencias Económicas y Estadísticas. Universidad Nacional de Rosario. 